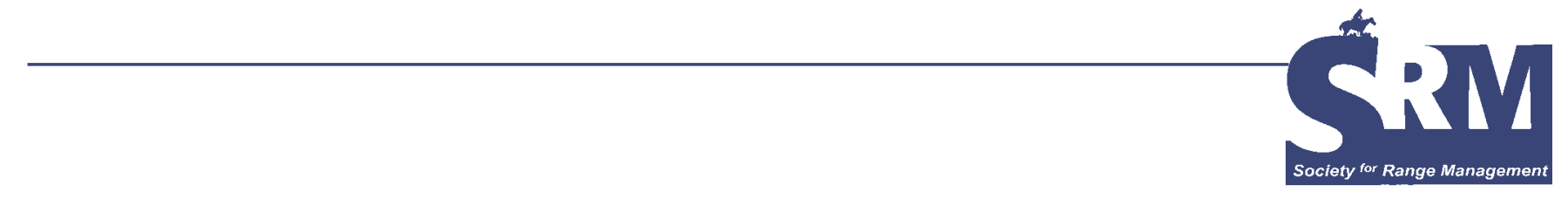

\title{
2008 Rangeland Cup
}

\section{Brian and Rachel Mealor, Rangeland Cup Competition, Co-Chairs}

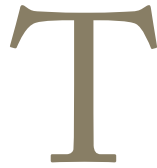

he Rangeland Cup team problem solving competition is an activity to promote critical thinking and cooperative, collaborative work on current topics and/or topics of historical importance to rangeland ecology and management. As we progress in our careers, much of our work is performed as part of a group. This competition is intended to build skills in interpersonal communication and group problem solving, both of which are highly desired qualities in the workplace. At the 2008 Annual SRM meeting in Louisville, Kentucky, eight institutions entered teams into the Rangeland Cup competition. All posters were well-prepared and presented. Each team presented their solution to the following challenge:

Livestock grazing and rangelands have historically been connected in perception, and often in definition. Management of rangelands increasingly, however, emphasizes multiple uses that often include conservation goals.

What role does livestock grazing play in the long-term conservation of rangelands? What are the benefits and consequences of livestock grazing in this contemporary conservation-livestock production interface? Explain your answer using support from scientific literature. Design an educational program to inform those people who may not be familiar with rangeland ecology and management about your concept of the relationship between livestock grazing and rangeland conservation.

The abstracts that follow provide summaries of the top teams' winning presentations. Please find more information regarding these projects at www.rangelands.org and be sure to attend the Rangeland Cup competition at the upcoming annual meeting in Albuquerque, New Mexico.

\section{First Place: Utah State University}

Team Members (left to right): Casey Addy, Ashley Hansen, and Katie Santini

Team Advisor (right): Chris Call

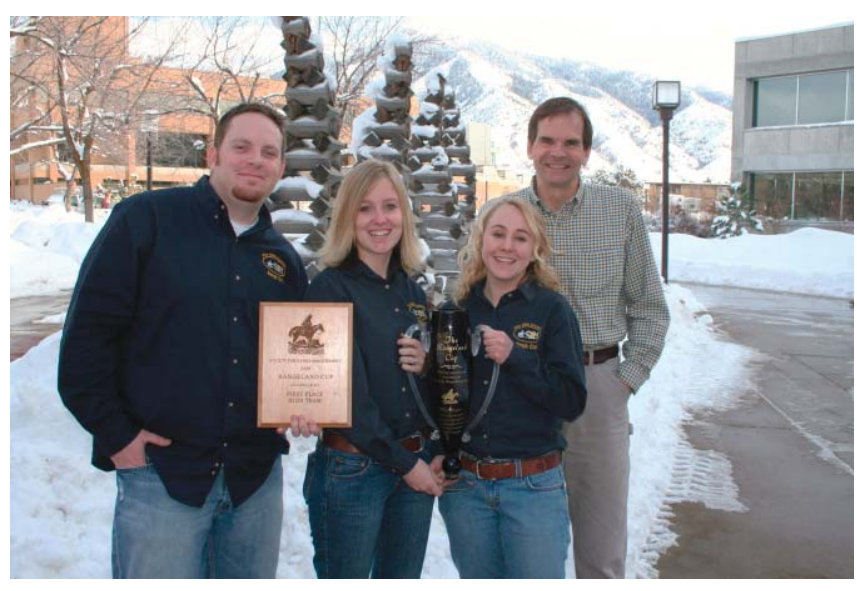

Conservation Cowboys: Innovative Grazing

Management for Multiple Values

This poster was designed to show the importance of conservation of rangelands for multiple uses, emphasizing open space and biodiversity in contemporary society. To do this, both the benefits and consequences of livestock grazing must be recognized. Three case studies in northern Utah were used to demonstrate how conservation and livestock can coexist. These included Harold B. Selman Inc, a 40,000acre family ranch; the Great Salt Lake Shorelands Preserve, 6,000 acres of critical wetlands owned by The Nature Conservancy; and Deseret Land and Livestock, a 200,000acre ranch owned by the Church of Jesus Christ of Latter 
Day Saints. The Nature Conservancy and Selman operations use conservation easements to preserve open space, and all three operations use livestock grazing to improve wildlife habitat and manage undesirable plants. These operations and their managers share four common attributes that we deemed important for successful rangeland management in contemporary society: stewardship, profitability, communication, and flexibility/innovation. We also designed a framework, with formal and informal components, for educating the public about rangeland ecology and management, and the relationship between livestock grazing and rangeland conservation. The formal component included a curriculum for 9th grade science and agriculture courses. The informal component included a website and a traveling exhibit that could be displayed at libraries, museums, and nature preserves.

\section{Second Place: Montana State University}

Jessica Davis (pictured)

Mentor: Dr Clayton Marlow

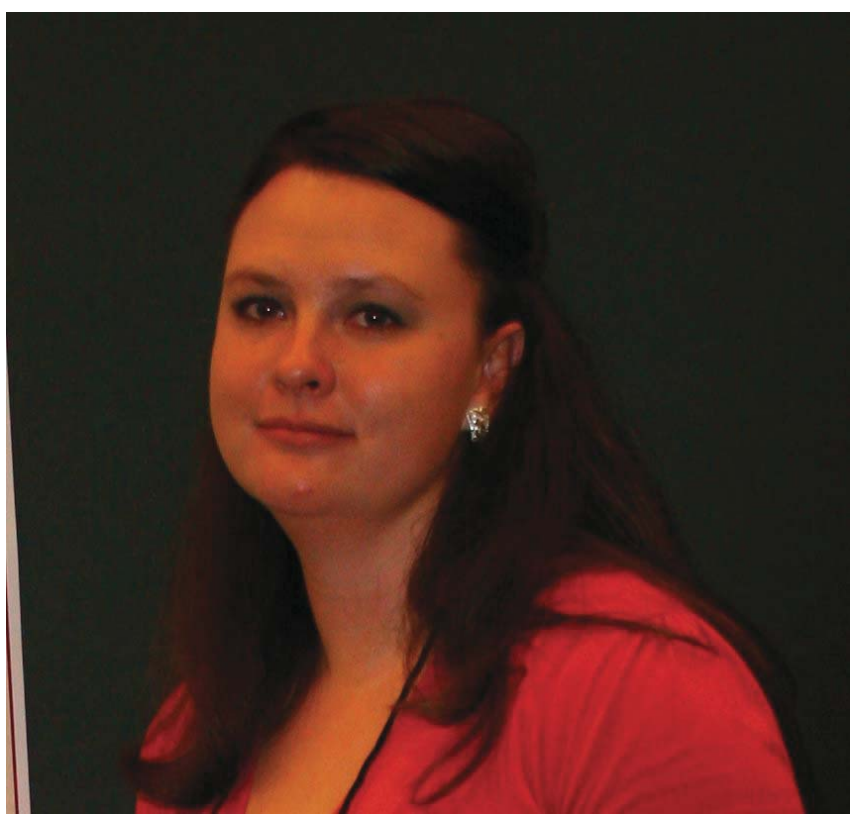

\section{Educating for the Future of Our Rangelands}

Well-managed livestock grazing can lead to the conservation of natural resources. Rangelands provide a way for plant materials to be used to produce food and fiber for human consumption with few inputs. As the world's population continues to grow, it is important that we utilize natural resources sustainably. The general public is not familiar with the benefits that grazing on rangelands can provide for both societal needs and values. It is important that we start the educational process with our future, the young individuals that will be making the policy and management decisions determining the future of our rangelands and communities. In order to educate these young individuals, an education program was developed to be implemented as a component of a middle school science class curriculum. The lesson plan can be easily adapted for a number of age groups. It was designed to enhance the understanding that properly managed livestock grazing can lead to conservation of natural resources.

\section{Third Place: Chadron State College}

Team Members: Andrew Houser, Kristy Kemp, Justin Lemmer, and Amy Tullis

Team Mentor: Georgia Younglove

\section{Range Management as We See it Today}

Our poster was designed to show the evolution of the native range that developed under grazing. Our main ideas showed the history of grazing, benefits and consequences, trend worksheets, and contemporary grazing management. This poster educates those not familiar with rangeland ecology and management. Educating the general public about the evolution of rangeland management and conservation practices, which go hand-in-hand with livestock grazing, is imperative to the long-term sustainability of our native rangelands.

Editor's Note: This article on SRM student activities was edited and compiled by Kim McReynolds, Rangelands Editor for Student Activities. Available Rangeland Cup posters can be viewed online in the student section at www.rangelands.org. 